\title{
Pembentukan Karakter Siswa Pada Pembelajaran Bahasa Indonesia Berbasis Kearifan Lokal
}

\author{
Muh. Irfan*, Edi Firmansyah, Nasruddin, Muhammad Wahyu Setiyadi \\ STKIP Al Amin Dompu, Indonesia \\ *imuh0492@gmail.com
}

\begin{abstract}
This study aims to describe the character building of students in Indonesian language learning based on local wisdom. The approach used is qualitative and quantitative with descriptive types. The subjects of this study were 32 students of $M A N$ Dompu. Data obtained through a Likert scale type questionnaire. The results of the study show that learning Indonesian based on local wisdom can have a very positive impact on the formation of student characteristics. The statement is based on the results of data analysis which reveal that each indicator of student character formation is: 1) Honest with an average score of 2.35 and the category is quite good; 2) Creative with an average score of 2.53 and the category is quite good; 3) Responsibility with an average score of 2.51 and good category; and 4) Tolerance with an average score of 2.62 and a good category, indicating that students have a fairly good or positive level of character in learning Indonesian based on local wisdom as seen in each indicator.
\end{abstract}

Keywords: local culture; character building; indonesian language

\begin{abstract}
ABSTRAK
Penelitian ini bertujuan mendeskripsikan pembentukan karakter siswa pada pembelajaran bahasa indonesia berbasis kaarifan lokal. Pendekatan yang digunakan adalah kualitatif dan kuantitatif dengan jenis deskriptif. Subjek penelitian ini yaitu 32 siswa MAN Dompu. Data diperoleh melalui angket jenis Skala Likert. Hasil penelitian menunjukan bahwa pada pembelajaran bahasa indonesia yang berbasis kearifan lokal dapat meberikan dampak yang sangat positif terhadap pembentukan karaker siswa. Pernyataan tersebut didasari oleh hasil analisis data yang mengungkapkan bahwa pada setiap indikator pembentukan karaker siswa yaitu: 1) Jujur dengan perolehan skor rata-rata sebesar 2,35 dan kategori cukup baik; 2) Kreatif dengan perolehan skor rata-rata sebesar 2,53 dan kategori cukup baik; 3) Tanggung Jawab dengan perolehan skor rata-rata sebesar 2,51 dan kategori baik; dan 4) Toleransi dengan perolehan skor rata-rata sebesar 2,62 dan kategori baik, menunjukan bahwasanya siswa memiliki tingkat karakter yang cukup baik atau positif pada pembelajaran bahasa indonesia berbasis kearifan lokal yang terlihat pada masing-masing indikator.
\end{abstract}

Kata Kunci: kearifan lokal; pembentukan karakter; bahasa Indonesia.

Submitted Mar 12, 2021 | Revised Mar 21, 2021 | Accepted Mar 28, 2021

\section{Pendahuluan}

Pendidikan berakar pada budaya bangsa untuk membentuk karakter bangsa masa kini dan masa mendatang (Handayani, Soesilowati, \& Priyanto, 2018). Pandangan ini menjadikan Kurikulum terus dikembangkan berdasarkan budaya bangsa yang beragam, diarahkan untuk membangun kehidupan masa kini, dan untuk membangun dasar bagi kehidupan bangsa yang lebih baik di masa depan (Okoye, 2014). Mempersiapkan peserta didik untuk kehidupan masa depan selalu menjadi kepedulian kurikulum (Nasab, 2015; Okoye, 2014). Hal ini mengandung makna bahwa kurikulum adalah rancangan pendidikan untuk mempersiapkan kehidupan generasi muda bangsa (Nasab, 2015; Springfield, Rodger, \& Gustafsson, 2017).

Pendidikan karakter merupakan proses mendidik dan mengatur sikap seseorang agar memiliki kepribadian yang baik (Karagiannopoulou, 2019). Pendidikan karakter merupakan Pembentukan karakter atau carakter building sedang menjadi sorotan dari banyak pihak termasuk terutama orang tua yang ingin anak-anak mereka memiliki berkarakter baik atau positif (Karagiannopoulou, 2019). Karakter yang bernilai positif dapat ditunjukan ketika seorang anak memiliki watak dan prilaku yang baik dalam kehidupan baik dalam bermasyarkat, berbangsa dan bernegara (Virgiyanti, Widiati, Bahasa, 
\& Suharmanto, 2016). Karakter positif akan melahirkan sorang siswa yang memiliki dedikasi yang tinggi dalam hal belajar baik dilingkungan sekolah maupun diluar lingkungan sekolah (Handayani et al., 2018). Sehingga karakter sangat dibutuhkan dalam pembelajaran (Anwar, 2017). Hal tersebut dapat membuat pindidikan karakter menjadi penting dalam dunia pendidikan (Handayani et al., 2018; Virgiyanti et al., 2016).

Salah satu Peraturan pemerintah tentang Standar Kompetensi yakni dimensi sikap dan mempunyai kualifikasi kemampuan yang diharapkan yaitu memiliki perilaku yang mencerminkan sikap orang beriman dan bertakwa kepada Tuhan YME dan erkarakter baik (Handayani et al., 2018). Sehingga pendidikan karakter sejak dini pada anak adalah langkah awal dari pembentukan karakter anak sehingga diperlukanya pendidikan sejak dini. Pentingnya penanganan terhadap rendahnya kualitas karakter yang dialami oleh anak-anak pada era globalisasi ini dapat dilakukan dengan menggunakan media-media pembelajaran yang berbasis kearifan lokal dari daerah masing-masing sebagai acuan dalam berkehidupan di masyarakat (Ratih \& Suryana, 2020).

Kearifan lokal atau dalam bahasa asing disebut dengan "local wisdom" merupakan bagian penting yang tidak dapat dipisahkan dari masyarakat (Danoebroto, Suyata, \& Jailani, 2019). Kearifan lokal adalah pandangan hidup masyarakat dan segala seusatu yang terkait dengan cara hidup masyarakat yang berwujud aktivitas yang dilakukan oleh masyarakat lokal dalam menjawab berbagai masalah dalam pemenuhan kebutuhan mereka (Njatrijani, 2018). Kearifan lokal adalah segala aspek pengetahuan, keyakinan, pemahaman atau wawasan dan etika yang menuntun perilaku manusia dalam kehidupan di dalam komunitas ekologis (Danoebroto et al., 2019). Kearifan lokal ini dihayati, dipraktekkan, diajarkan dan diwariskan dari generasi ke generasi sekaligus membentuk pola perilaku manusia terhadap sesama manusia (Danoebroto et al., 2019; Khusna, Shufa, \& Artikel, 2018).

Pembelajaran yang berbasis kearifan lokal dapat menanamkan nila-nilai dan norma-norma pada setiap peserta didik (Njatrijani, 2018). Hal ini dapat memberikan dorongan dan motivasi terhadap siswa untuk belajar disekolah dan juga dapat diimplementasikan dikehidupan bermasayarakat (Khusna et al., 2018). Berdasarkan paparan bahwa pentingnya pendidikan karakter dan menfaat dari pembelajaran kearifan lokal. Maka penulis ingin meneliti bagaimana karakter siswa pada pembelajaran bahasa indonesia berbasis kearifan lokal.

\section{Metode Penelitian}

Penelitian ini menggunakan pendekatan kualitatif dan kuantitatif dengan jenis deskriptif. Subjek dalam penelitian ini yaitu 32 siswa di MAN Dompu. Data dikumpulkan melalui angket dengan jenis Skala Likert yang memuat pilihan jawaban "sangat setuju" dengan skor empat, "setuju" dengan skor tiga, "tidak setuju" dengan sekor dua, dan "sangat tidak setuju" dengan skor satu. Angket ditujukan kepada 32 orang siswa untuk memperoleh informasi mengenai pembentukan karakter siswa pada pembelajaran bahsa indonesia berbasis kearifan lokal. Teknik analisis data adalah dengan menggunakan reduksi data, penyajian data dan penarikan kesimpulan. Selain itu menggunakan rumus statistik deskriptif untuk mengetahui persetasi (\%) karakter siswa. Instrumen yang digunakan terdiri dari 20 item untuk memperoleh informasi tentang pembentukan karakter siswa pada pembelajaran bahasa indonesia berbasis kearifan lokal. Pembentukan karakter siswa memiliki banyak sekali indikator, namun pada penelitian ini menggunakan beberapa inbdikator yang dapat mewakili indikator pembentukan karakter yang dapat dijelaskan pada tabel berikut ini: 


\begin{tabular}{ccc} 
Table 1 & \multicolumn{2}{c}{ Distribusi Jumlah Item Angket } \\
\hline \multirow{2}{*}{ Indikator } & \multicolumn{2}{c}{ Jumlah Item } \\
\cline { 2 - 3 } & Positif & Negatif \\
\hline Jujur & 4 & 1 \\
Kreatif & 3 & 2 \\
Tanggung Jawab & 3 & 2 \\
Toleransi & 3 & 2 \\
\hline
\end{tabular}

\section{Hasil dan Pembahasan}

Analisis data pada penelitian ini diperoleh berdasarkan hasil pada penelitian yang dilakukan dengan memberikan angket kepada siswa untuk memperoleh informasi terkait pembentukan karakter siswa pada pembelajaran bahasa indonesia berbasis kearifan lokal.

Data pembentukan karakter siswa pada pembelajaran bahasa indonesia berbasis kearifan lokal diperoleh dengan menggunakan angket tertutup dengan jenis skala likert. Pengukuran pembentukan karakter siswa menggunaan beberapa indikator yaitu: 1) jujur; 2) kreatif: 3) tanggung jawab; 4) toleransi. Berikut hasil analisis dari angket pembentukan karakter siswa yang ditunjukan pada tabel barikut.

Table 2 Indikator Jujur Siswa Pada Pembelajaran Bahasa Indonesia Berbasis Kearifan Lokal

\begin{tabular}{|c|c|c|c|c|c|c|}
\hline \multirow{2}{*}{ No } & \multirow{2}{*}{ Item } & \multicolumn{4}{|c|}{ Opsi } & \multirow{2}{*}{ Mean } \\
\hline & & SS & S & TS & STS & \\
\hline \multirow[t]{2}{*}{1} & Mencontek adalah sikap yang memebohongi & 9 & 13 & 8 & 2 & 2,90 \\
\hline & diri sendiri & $28,12 \%$ & $40,62 \%$ & $25 \%$ & $6,26 \%$ & \\
\hline \multirow[t]{2}{*}{2} & Saya selalu mengembalikan barang yang & 12 & 11 & 7 & 2 & 3,03 \\
\hline & bukan menjadi milik saya & $37,5 \%$ & $34,37 \%$ & $21,87 \%$ & $6,25 \%$ & \\
\hline \multirow[t]{2}{*}{3} & Saya selalu berkata jujur dan mengatakan & 10 & 11 & 9 & 2 & 2,90 \\
\hline & sesuatu sesuai fakta & $31,27 \%$ & $34,37 \%$ & $28,12 \%$ & $6,25 \%$ & \\
\hline \multirow[t]{2}{*}{4} & Saya tidak melaporkan kepada guru ketika & 2 & 2 & 13 & 15 & 1,71 \\
\hline & saya menemukan barang orang lain yang jatuh & $6,25 \%$ & $6,25 \%$ & $40,62 \%$ & $46,87 \%$ & \\
\hline \multirow[t]{2}{*}{5} & Saya selalu berbohong kepada siapapun & 0 & 0 & 6 & 26 & 1,18 \\
\hline & disekolah & $0 \%$ & $0 \%$ & $18,75 \%$ & $81,25 \%$ & \\
\hline \multirow{2}{*}{\multicolumn{2}{|c|}{ Rata-rata }} & 6,6 & 7,4 & 8,6 & 9,4 & 2,35 \\
\hline & & $20,62 \%$ & $23,12 \%$ & $26,87 \%$ & $29,37 \%$ & \\
\hline
\end{tabular}

Hasil analisis pada tabel di atas menunjukkan bahwa indikator jujur pada pembelajaran bahasa indonesia memperoleh nilai rata-rata skor 2,35 dan termasuk pada kategori cukup baik. Pada indikator ini, terdapat beberapa item pernyataan yang item yang menunjukan kategori kurang yaitu item empat dan lima. Kedua item tersebut masing-masing memperoleh rata-rata skor 1,71 dan 1,18. Hal ini menandakan bahwasanya siswa tidak setuju dengan pernyataan bahwa mereka tidak melaporkan pada guru apabila melihat barang orang lain yang jatuh dan tidak setuju apabila mereka selalu berbohong pada siapapun. Item yang mendapat skor rata-rata tertinggi yaitu 3,03 tergolong kategori baik pada item tiga menunjukan bahwa siswa selalu mengembalikan barang yang bukan menjadi milik mereka.

Table 3 Indikator Kreatif Siswa Pada Pembelajaran Bahasa Indonesia Berbasis Kearifan Lokal

\begin{tabular}{clccccc}
\hline \multirow{2}{*}{ No } & \multirow{2}{*}{ Item } & \multicolumn{4}{c}{ Opsi } & \multirow{2}{*}{ Mean } \\
\cline { 3 - 6 } & & SS & S & TS & STS & \\
\hline \multirow{2}{*}{1} & Saya tidak malu untuk menyampaikan & 14 & 13 & 5 & 0 & 3,28 \\
& sanggahan terhadap pendapat teman & $43,75 \%$ & $40,62 \%$ & $15,62 \%$ & $0 \%$ & \\
\hline
\end{tabular}


dari kelompok lain pada waktu presentasi.

2 Saya mencoba berpikir sendiri terlebih dahulu ketika mengerjakan soal yang diberikan guru sebelum melakukan diskusi

3 Saya putus asa jika dalam menyelesaikan tugas kelompok kearifan lokal yang diberikan guru

4 Saya malu bertanya kepada guru jika ada materi yang belum saya pahami pada waktu diskusi kelompok.

5 Ketika mengerjakan tugas kelompok bahasa indonesia berbasis kearifan lokal saya dapat menemukan pengetahuan $\begin{array}{ccccc}7 & 16 & 8 & 1 & 2,90 \\ 21,87 \% & 50 \% & 25 \% & 3,12 \%\end{array}$

$\begin{array}{ccccc}1 & 1 & 16 & 14 & 1,65 \\ 3,12 \% & 3,12 \% & 50 \% & 43,75 \% & \end{array}$

dan ide-ide baru untuk tugas saya

\begin{tabular}{rrrrrr} 
Rata-rata & 6,2 & 10,6 & 9,4 & 5,8 & 2,53 \\
& $19,37 \%$ & $33,12 \%$ & 29,37 & $18,12 \%$ & \\
\hline
\end{tabular}

indikator kreatif siswa pada pembelajaran bahasa indoenasi berbasis kearifan lokal. Pada indikator ini mempunyai rata-rata skor 2,53 dan kategori baik. Terdapat dua item yaitu item delapan dan sembilan yang menunjukan kategori kurang yang menandakan siswa tidak setuju jika mereka putus asa dalam menyelesaikan tuga yang diberikan guru dan mereka malu untuk bertanya kepada guru ataupun teman. Sebaliknya mereka selalu aktif bertanya jika ada yang belum mereka pahami. Item ini memperoleh nilai rata-rata yang tinggi yaitu 3,28 yaitu item enam dengan kategori baik.

Table 4 Indikator Tanggung Jawab Siswa Pada Pembelajaran Bahasa Indonesia Berbasis Kearifan Lokal

\begin{tabular}{|c|c|c|c|c|c|c|}
\hline \multirow{2}{*}{ No } & \multirow{2}{*}{ Item } & \multicolumn{4}{|c|}{ Opsi } & \multirow{2}{*}{ Mean } \\
\hline & & SS & $\mathrm{S}$ & TS & STS & \\
\hline 1 & $\begin{array}{l}\text { Saya berani mengakui kesalahan yang } \\
\text { telah saya lakukan dan berusaha } \\
\text { memperbaikinva }\end{array}$ & $\begin{array}{c}9 \\
28,12 \%\end{array}$ & $\begin{array}{c}13 \\
40,62 \%\end{array}$ & $\begin{array}{c}8 \\
25 \%\end{array}$ & $\begin{array}{c}2 \\
6,26 \%\end{array}$ & 2,90 \\
\hline 2 & $\begin{array}{l}\text { Saya selalu mengumpulkan tugas } \\
\text { kelompok bahasa indonesia berbasis } \\
\text { kearifan lokal secara individu maupun } \\
\text { dengan tepat waktu }\end{array}$ & $62,5 \%$ & $\begin{array}{c}12 \\
37,5 \%\end{array}$ & $\begin{array}{c}0 \\
0 \%\end{array}$ & $\begin{array}{c}0 \\
0 \%\end{array}$ & 3,62 \\
\hline 3 & $\begin{array}{l}\text { Saya selalu berperan aktif dalam } \\
\text { kegiatan belajar mengajar bahasa } \\
\text { indonesia berbasis kearifan lokal dikelas } \\
\text { mauoun dluar kelas }\end{array}$ & $\begin{array}{c}10 \\
31,27 \%\end{array}$ & $\begin{array}{c}13 \\
40,62 \%\end{array}$ & $\begin{array}{c}9 \\
28,12 \%\end{array}$ & $\begin{array}{c}0 \\
0 \%\end{array}$ & 3,03 \\
\hline 4 & $\begin{array}{l}\text { Saya tidak hadir ketika saya bertugas } \\
\text { melakukan presentasi proyek kearifan } \\
\text { lokal yang diberikan oleh guru }\end{array}$ & $\begin{array}{c}0 \\
0 \%\end{array}$ & $\begin{array}{c}0 \\
0 \%\end{array}$ & $\begin{array}{c}15 \\
46,87 \%\end{array}$ & $\begin{array}{c}17 \\
53,12 \%\end{array}$ & 1,46 \\
\hline 5 & $\begin{array}{l}\text { Saya tidak berusaha dan tidak memiliki } \\
\text { inisiatif dalam mengatasi suatu masalah } \\
\text { pada pembelajaran bahasa indonesia } \\
\text { berbasis kearifan lokal. }\end{array}$ & $0 \%$ & $0 \%$ & $53,12 \%$ & $\begin{array}{c}15 \\
46,87 \%\end{array}$ & 1,53 \\
\hline & Rata-rata & $\begin{array}{c}7,8 \\
24,37 \%\end{array}$ & $\begin{array}{c}7,6 \\
23,75 \%\end{array}$ & $\begin{array}{c}9,8 \\
30,62 \%\end{array}$ & $\begin{array}{c}6,8 \\
21,25\end{array}$ & 2,51 \\
\hline
\end{tabular}


Berdasarkan hasil analisis data pada indikator Tanggung Jawab Siswa Pada Pembelajaran Bahasa Indonesia Berbasis Kearifan Lokal memperoleh skor rata-rata 2,51 dan memperoleh kategori cukup baik. Terdapat dua item yaitu item 14 dan 15 yang menunjukan kategori kurang yang menandakan siswa tidak setuju bahwasanya mereka tidak hadir ketika bertugas untuk presentasi dan tidak memiliki inisiatif untuk mengatasi masalah dalam pembelajaran bahasa indonesia berbasis kearifan lokal. Item yang mendapat skor rata-rata tertinggi yaitu 3,03 yang tergolong kategori baik yang menunjukan bahwa siswa selalu berperan aktif dalam kegiatan belajar mengajar dikelas bahasa indonesia berbasis kearifan lokal.

Table 5 Tabel 5. Indikator Toleransi Siswa Pada Pembelajaran Bahasa Indonesia Berbasis Kearifan Lokal

\begin{tabular}{|c|c|c|c|c|c|c|}
\hline \multirow{2}{*}{ No } & \multirow{2}{*}{ Item } & \multicolumn{4}{|c|}{ Opsi } & \multirow{2}{*}{ Mean } \\
\hline & & SS & S & TS & STS & \\
\hline \multirow[t]{2}{*}{1} & Saya tidak mengganggu teman apabila teman & 20 & 11 & 1 & 0 & 3,59 \\
\hline & memiliki perbedaan pendapat & $62,5 \%$ & $34,37 \%$ & $3,12 \%$ & $0 \%$ & \\
\hline \multirow[t]{3}{*}{2} & Saya dapat menerima kekurangan dari teman & 28 & 4 & 0 & 0 & 3,87 \\
\hline & ketika mengerjakan tugas kelompok bahasa & $87,5 \%$ & $12,5 \%$ & $0 \%$ & $0 \%$ & \\
\hline & indonesia dan berusaha membimbingnya & & & & & \\
\hline \multirow[t]{3}{*}{3} & Saya tidak akan memaafkan kesalahan teman yang & 0 & 0 & 0 & 32 & 1 \\
\hline & melakukan kesalahan saat proses belajar mengajar & $0 \%$ & $0 \%$ & $0 \%$ & $100 \%$ & \\
\hline & bahasa indonesia & & & & & \\
\hline \multirow[t]{2}{*}{4} & Saya tidak mau bekerja sama dengan teman atau & 0 & 0 & 7 & 25 & 1,22 \\
\hline & orang lain yang berbeda keyakinan & $0 \%$ & $0 \%$ & $21,87 \%$ & $78,12 \%$ & \\
\hline \multirow[t]{2}{*}{5} & Saya terbuka maupun menerima hal baru dan & 18 & 10 & 4 & 0 & 3,44 \\
\hline & berusaha mempelajarinya & $56,25 \%$ & $31,25 \%$ & $12,5 \%$ & $0 \%$ & \\
\hline \multirow{2}{*}{\multicolumn{2}{|c|}{ Rata-rata }} & 13,2 & 5 & 2,4 & 11,4 & 2,62 \\
\hline & & $41,25 \%$ & $15,62 \%$ & $7,5 \%$ & $35,62 \%$ & \\
\hline
\end{tabular}

Indikator berikutnya yaitu toleransi siswa pada pembelajaran bahasa indonesia berbasis kearifan lokal. Tabel 5 di atas menunjukkan bahwa toleransi siswa pada pembelajaran bahasa indonesia berbasis kearifan lokal mempunyai rata-rata skor 2.62 dan termasuk kategori baik. Pada toleransi siswa pada pembelajaran bahasa indonesia berbasis kearifan lokal, terdapat dua item yaitu 18 dan 19 yang menunjukan kategori kurang yang menandakan siswa tidak setuju bahwa mereka tidak memaafkan kesalahan teman yang melakukan kesalahan dan selalu bekerja sama deangan teman yang memiliki keayakinan yang berbeda dengan mereka sendiri. Sedangkan item yang mendapat skor rata-rata tertinggi yaitu 3,87 yang tergolong kategori baik ditujunkan oleh item 17 dengan bukti bahwa mereka dapat menerima kekurangan dari teman ketika mengerjakan tugas kelompok bahasa indonesia dan berusaha membimbingnya

Secara keseluruhan, indikator karakter dengan rata-rata tertinggi yaitu indikator toleransi siswa pada pembelajaran bahasa indonesia berbasis kearifan lokal dengan rata-rata skor 2.62 dan termasuk kategori baik. Hal ini menunjukan bahwasanya pembelajaran bahasa indonesia berbasi kearifan lokal memiliki dampak positif pada indikator karakter siswa yaitu jiwa toleransi siswa. Sedangkan indikator karakter siswa dengan rata-rata terendah yaitu indikator tanggung jawab siswa pada pembelajaran bahasa indonesia berbasis kearifan lokal dengan rata-rata skor 2,51 akan tetapi termasuk dalam kategori cukup baik. Berdasarkan hal tersebut menunjukan bahwa penerapan pembelajaran bahasa indonesia berbasis kearifan lokal juga memiliki dampak positif pada indikator tanggung jawab.

Pendidikan karakter sangat penting dalam mengembangan karakteristik anak dalam menjalankan kehidupannya didunia pendidikan dan masyarakat. Pendidikan karakter mendefinisikan pendidikan karakter sebagai upaya yang dirancang secara sengaja untuk memperbaiki karakter para 
siswa (Astuti, Fauziati, \& Marmanto, 2019; Phala \& Chamrat, 2018). Guru sebagai pemdidik dituntun untuk dapat membimbing siswa sehingga dapat mimiliki karakter yang baik (Phala \& Chamrat, 2018).

Karakter siswa menjadi salah satu faktor yang dapat mempengaruhi bagaimana siswa dalam belajar. Beberapa hal yang dapat dipengharuhi adalah berkaitan dapat berupa bakat, minat, sikap, motivasi belajar, gaya belajar, kemampuan berfikir, dan kemampuan awal (Harisanti \& Anugrah, 2018). Karakteristik siswa akan amat berpengaruh dalam pemilihan strategi pengelolaan, yang berkaitan dengan bagaimana menata pembelajaran, khususnya komponen-komponen strategi pembelajaran, agar sesuai dengan karakteristik individu siswa (Harisanti \& Anugrah, 2018; Mustoip, 2018)

Mengingat pentingnya karaker dalam dunia dunia pendidikan ataupun bermasyarakat. Kearifan lokal sangat diperlukan dalam pendidikan, karena mengandung nilai-nilai kebaikan yang abadi dalam hubungannya dengan relasi keluarga, tetangga dan masyarakat lain (Prasetyo, 2016). Peran kearifan lokal secara kritis mengubah dan membentuk budaya lokal menjadi bermakna dan sesuai dengan kehidupan sosial dan budaya masyarakat .

Kualitas pendidikan diperoleh dari mutu sumber daya manusia. Sumber daya manusia yang masih rendah, yang berarti kualitas pendidikan saat ini mayoritas masih rendah. Pemahaman tentang perilaku siswa dalam proses belajar merupakan yang sangat penting terutama bagi guru (Parlindungan, Rifai, \& Safriani, 2018). Ada kecenderungan saat ini untuk kembali pada pemikiran bahwa anak akan lebih baik jika lingkungan diciptakan alamiah. Belajar akan lebih bermakna jika anak mengalami apa yang dipelajarinya, bukan mengetahuinya (Parlindungan et al., 2018). Proses pembelajaran berorientasi pada penguasaan materi yang bertujuan memotivasi siswa untuk memahami makna materi pelajaran yang dipelajarinya dengan mengaitkan materi tersebut dengan konteks kehidupan mereka sehari-hari atau yang juga bisa disebut dengan kearifan sehingga siswa memiliki pengetahuan yang secara fleksibel dapat diterapkan dari masalah ke masalah lainnya (Parlindungan et al., 2018; Tandiseru, 2016).

Kearifan adalah sebuah nilai universal tentang keadilan sosial, kesejahteraan masyarakat dan kelestraian sumberdaya penghidupan masyarakat yang menjadi dasar bagi hubungan antara kehidupan bermasyarakat (Simamora, Saragih, \& Hasratuddin, 2019; Tandiseru, 2016). Kearifan Lokal terdapat pada segala aspek kehidupan karena berasal dari budaya yang ada pada setiap daerah. Sehingga kegunaan kearifan lokal salah satunya adalah sebagai solusi alternatif dalam menangani permasalahan kehidupan (Samingin \& Asmara, 2016; Simamora et al., 2019). Kearifan lokal merupakan budaya masa lalu yang secara terus-menerus dijadikan pegangan hidup (Prasetyo, 2016). Meskipun bernilai lokal tetapi nilai yang terkandung di dalamnya dianggap sangat universal.

Pembelajaran berbasis kearifan lokal adalah cara pendidik mengajarkan peserta didik untuk selalu situasi konkret yang mereka hadapi (Zuchdi \& Nurhadi, 2019). Pendidikan dengan kearifan lokal perlu dikembangkan secara sinergis dalam pendidikan guna membentuk peserta didik yang berkarakter (Kartini, Tolla, Jasruddin, \& Juanda, 2019). Kearifan lokal disebut sebagai konten pembentukan karakter peseta didik yang nantinya bisa disisipkan dalam pembelajaran, ini dilakukan sehingga peserta didik lebih memaknai ataupun menghayatinya pembelajaran karena tidak lapas dari budaya ataupun lingkungan sekitar mereka (Mahmud, 2019)

\section{Kesimpulan}

Berdasarkan hasil penelitian menunjukan bahwa pada pembelajaran bahasa indonesia yang berbasis kearifan lokal dapat meberikan dampak yang sangat positif terhadap pembentukan karaker siswa. Pernyataan tersebut didasari oleh hasil analisis data yang mengungkapkan bahwa pada setiap indikator pembentukan karaker siswa yaitu: 1) Jujur; 2) Kreatif; 3) Tanggung Jawab; dan 4) Toleransi, menunjukan bahwasanya siswa memiliki tingkat karakter yang cukup baik atau positif pada pembelajaran bahasa indonesia berbasis kearifan lokal yang terlihat pada masing-masing indikator. Sehingga disarankan kepada pendidik untuk memanfaatkan, menerapkan ataupun menggunakan pembelajaran berbasis kearifan lokal khususnya pembelajaran bahasa indonesia. 


\section{Daftar Pustaka}

Anwar, M. K. (2017). Pembelajaran Mendalam untuk Membentuk Karakter Siswa sebagai Pembelajar. Tadris: Jurnal Keguruan Dan Ilmu Tarbiyah, 02(2), 97-104. https://doi.org/10.24042/tadris.v2i2.1559

Astuti, D., Fauziati, E., \& Marmanto, S. (2019). Celebrating Students ' Diversities Through Understanding Students' Characteristics. International Online Journal of Education and Teaching (IOJET), 6(4).

Danoebroto, S. W., Suyata, \& Jailani. (2019). Teacher' S Belief Of Mathematical Literacy Based On Local Culture: Case Study Of Junior High School Mathematics Teacher Teacher' S Belief Of Mathematical Literacy Based On Local Culture : Case Study Of Junior High School Mathematics Teacher. In 6th International Conference on Mathematics, Science, and Education (ICMSE 2019). https://doi.org/10.1088/1742-6596/1567/3/032008

Handayani, T., Soesilowati, E., \& Priyanto, A. S. (2018). Student Character Buliding Reconstruction Junior High School in District Galesong Takalar Based Values National Culture. Journal of Educational Social Studies, 7(2), 116-122.

Harisanti, D., \& Anugrah, E. P. (2018). Characteristics of Senior High School Students in the Utilization of School Library in Indonesia. International Journal of Engineering \& Technology, 7(3), $206-210$.

Karagiannopoulou, E. (2019). Students ' Learning Characteristics , Perceptions of Small-Group University Teaching, and Understanding Through a " Meeting of Minds ." Frontiers in Psychology, 10(1). https://doi.org/10.3389/fpsyg.2019.00444

Kartini, Tolla, A., Jasruddin, \& Juanda. (2019). The Design of Local Culture-based Indonesian Language Teaching Materials. Journal of Language Teaching and Research, 10(2), 363-371.

Khusna, N., Shufa, F., \& Artikel, S. (2018). Pembelajaran Berbasis Kearifan Lokal Di Sekolah Dasar: Sebuah Kerangka Konseptual. Inopendas Jurnal Ilmiah Kependidikan, 1(1), 48-53.

Mahmud, Y. S. (2019). The Representation Of Local Culture In Indonesian Efl Textbooks : Rationales And Implications. Indonesian EFL Journal (IEFLJ), 5(2). https://doi.org/10.25134/ieflj.v5i2.1727.Received

Mustoip, S. (2018). Character Education Implementation For Students In Grade Iv Sdn 5 Sindangkasih Regency Of Purwakarta West Java. Premiere Educandum: Jurnal Pendidikan Dasar Dan Pembelajaran, 8(2), 112-126. https://doi.org/10.25273/pe.v8i2.2739

Nasab, F. G. (2015). Alternative versus Traditional Assessment. Journal of Applied Linguistics and Language Research, 2(6), 165-178.

Njatrijani, R. (2018). Kearifan Lokal Dalam Perspektif Budaya Kota Semarang Gema Keadilan Edisi Jurnal Gema Keadilan Edisi Jurnal. Gema Keadilan, 5(1), 16-31.

Okoye, M. D. (2014). Authentic Assessment and Evaluation : Paramount Means for the Maximization of Teaching and Learning. Journal of Educational and Social Research, 4(7), 31-40. https://doi.org/10.5901/jesr.2014.v4n7p31

Parlindungan, F., Rifai, I., \& Safriani, A. (2018). The representation of Indonesian cultural diversity in middle school English textbooks. Indonesian Journal Of Applied Linguistics, 8(2), 289-302. https://doi.org/10.17509/ijal.v8i2.13276

Phala, J., \& Chamrat, S. (2018). Learner Characteristics as Consequences of Active Learning. In International Annual Meeting on STEM Education (I AM STEM). https://doi.org/10.1088/17426596/1340/1/012083

Prasetyo, A. (2016). Folklore in EFL: The Local Wisdom Implementation of Indonesian Curriculum. Journal Of ELT Research, 1(2), 194-199.

Ratih, D., \& Suryana, A. (2020). Nilai-Nilai Kearifan Lokal Leuweung Gede Kampung Kuta Ciamis 
Dalam Mengembangkan Green Bihavior Untuk Meningkatkan Karakter Mahasiswa. Jurnal Artefak, 7(2), 141-152.

Samingin, F., \& Asmara, R. (2016). Eksplorasi Fungsi dan Nilai Kearifan Lokal Dalam Tindak Tutur Melarang di Kalangan Penutur Bahasa Jawa Dialek Standar. Transformatika, 12(1), 28-43.

Simamora, R. E., Saragih, S., \& Hasratuddin. (2019). Improving Students' Mathematical Problem Solving Ability and Self-Efficacy through Guided Discovery Learning in Local Culture Context. International Electronic Journal Of Mathematics Education, 14(1), 61-72.

Springfield, L., Rodger, S., \& Gustafsson, L. (2017). Threshold Concepts and Authentic Assessment: Learning to Think Like an Occupational Therapist. Practice and Evidence of Scholarship of Teaching and Learning in Higher Education, 12(2).

Tandiseru, S. R. (2016). The Effectiveness of Local Culture-Based Mathematical Heuristic-KR Learning towards Enhancing Student's Creative Thinking Skill. Journal of Education and Practice, 6(12), 74-82.

Virgiyanti, D. F., Widiati, U., Bahasa, P., \& Suharmanto. (2016). Characteristics Of Effective Junior High School English Teachers In Kabupaten Pacitan Based On Students' And Teachers '. Jurnal Pendidikan: Teori, Penelitian, Dan Pengembangan, 1(3), 338-346.

Zuchdi, D., \& Nurhadi. (2019). Culture Based Teaching And Learning For Indonesian As A Foreign Language In Yogyakarta. Cakrawala Pendidikan, 38(3), 465-476. https://doi.org/10.21831/cp.v38i3.26297 